\title{
LIXO ELETRÔNICO E A CONTRIBUIÇÃO DA POPULAÇÃO COM O MEIO AMBIENTE EM PRESIDENTE PRUDENTE
}

\author{
Nádia de Souza Bastos (1); Leila Maria Sotocorno e Silva (2); Rebeca Delatore S. Guerino (3) \\ (1) Curso de Graduação em Engenharia Ambiental - Faculdade de Engenharia de Presidente Prudente/UNOESTE - e-mail: \\ nadibastos@hotmail.br. (2) Docente da Faculdade de Engenharia Ambiental de Presidente Prudente/UNOESTE - e-mail: \\ leilamaria@unoeste.br. (3) Docente da Faculdade de Engenharia Ambiental de Presidente Prudente/UNOESTE - e-mail:
} rebeca@unoeste.br

\section{RESUMO}

O presente trabalho objetivou avaliar o nível de consciência ambiental da população de Presidente Prudente em relação ao descarte de resíduos eletroeletrônicos. Foi aplicado um questionários a 73 pessoas que participaram do Mutirão do Lixo Eletrônico, com questões relativas ao descarte do e-lixo. A maioria dos entrevistados era do sexo masculino (73\%), com idade entre 41 e 55 anos $(40 \%)$ e conhecedora do evento através da televisão. O motivo, apontado pelos entrevistados, para participação ao evento foi o desejo de se desfazer de tais materiais, sobretudo em seus lares. Foi observado que de maneira geral, os prudentinos entrevistados apresentaram nível satisfatório de consciência ambiental, haja vista que $89 \%$ deles afirmaram não descartar resíduos eletroeletrônicos no lixo comum.

Palavras-chave: Resíduos Eletroeletrônicos, Consciência Ambiental, Presidente Prudente.

\section{ELETRONIC TRASH AND THE CONTRIBUTION OF POPULATION TO THE ENVIRONMENT IN PRESIDENTE PRUDENTE}

\begin{abstract}
This study aimed to evaluate the level of environmental consciousness of the population of Presidente Prudente in relation to the discard of electronics residues. It was applied a questionnaire to 73 people who participated in the Task Force Electronic Trash with questions relating to the discard of e-trash. Most interviewed were male $(73 \%)$ with aged between 41 and 55 years $(40 \%)$ and knowledgeable of the event on television. The reason mentioned by the interviewed for participation in the event was the desire to dispose of such materials, especially in their homes. It was observed that in general the prudentinos interviewed had satisfactory level of environmental consciousness, considering that $89 \%$ of them said they did not discard electronic trash in the common trash.
\end{abstract}

Key words: electronics residues, environmental consciousness, Presidente Prudente. 


\section{INTRODUÇÃO}

Como resultado da utilização dos recursos naturais pelo homem surge a poluição. O aumento populacional e a forte industrialização estão ocasionando uma geração explosiva de resíduos, que são descartados, na maioria das vezes, de forma inadequada no meio ambiente (FERREIRA; FERREIRA, 2008).

A partir da industrialização tecnológica capitalista, surgiram, com objetivo de facilitar e agilizar as atividades humanas, os aparelhos eletroeletrônicos. De acordo com a Revista Meio Ambiente Industrial (QUINTALHINA, 2009), aparelhos eletroeletrônicos são produtos tecnologicamente desenvolvidos para atender à demanda de um novo mundo, como: televisores, rádios, telefones celulares, eletrodomésticos portáteis, equipamentos de informática, MP3s, i-pods, filmadoras, ferramentas elétricas, DVDs, lâmpadas fluorescentes, brinquedo eletrônicos, etc.

Existem diferentes tipos de poluição, da água, solo, ar e outras, mas é nesse contexto que surge a poluição eletrônica. Os lixos eletroeletrônicos são considerados como aqueles aparelhos que são dados por inúteis, supérfluos, e que quando descartados são chamados de Resíduos de Equipamentos Elétricos e Eletrônicos (Reee's), ou ainda, sucata eletrônica, lixo eletrônico ou e-lixo (QUINTALHINA, 2009). Entretanto, esses equipamentos eletroeletrônicos tornam-se "lixo" em um período de tempo relativamente pequeno, pois grande é o ritmo das inovações tecnológicas dos mesmos que acabam por incentivar 0 consumismo (FERREIRA; FERREIRA, 2008).

"O descarte de resíduos sólidos por parte de pessoas e organizações é natural.
Contudo, quando o volume empresarial é grande, evidencia-se desperdício, que, no âmbito residencial, é indicador de consumismo." (GIACOMINI, 2008, p. 67).

Segundo a Fundação Estadual do Meio Ambiente (2009), o Brasil descarta em torno de $680 \mathrm{mil}$ toneladas de resíduos eletroeletrônicos.

Os equipamentos eletroeletrônicos são constituídos por diferentes materiais, que poderiam ser reciclados, e elementos, como: vidro, plásticos, metais ferrosos e nãoferrosos, mercúrios, berílio, chumbo, e outros. Alguns desses elementos são acumulativos e podem causar graves danos ao ecossistema e ao homem.

A Lei $n^{\circ}$. 12.305 de 02 de agosto de 2010 instituiu a Política Nacional dos Resíduos Sólidos, que visa, dentre seus objetivos, a não geração, redução, reutilização, reciclagem e tratamento dos resíduos sólidos, bem como disposição final ambientalmente adequada dos rejeitos. E foi diante dessa premissa que o presente trabalho foi realizado, com o objetivo de avaliar o nível da consciência ambiental da população de Presidente Prudente quanto ao descarte dos resíduos eletroeletrônicos.

\section{METODOLOGIA}

Com o intuito de avaliar a percepção ambiental do público participante do evento e realizar trabalho de educação ambiental foram realizadas as etapas que serão mais bem detalhadas a seguir.

\section{Evento}

No dia 26 de junho de 2010 das 8 h às $17 \mathrm{~h}$, foi realizado a $3^{\text {a }}$ edição do Mutirão do Lixo Eletrônico no Parque do Povo de Presidente Prudente. O evento foi organizado 
pela Secretaria de Tecnologia da Informação da Prefeitura de Presidente Prudente (SETEC) e com o apoio da Faculdade de Informática de Presidente Prudente (FIPP) e da Universidade do Oeste Paulista (UNOESTE).

Todas as pessoas que participaram do evento receberam cupons para concorrer a dez bicicletas, um videogame, um netbook, camisetas, bonés, papapilhas.

Alunos do curso de Engenharia Ambiental e Agronomia da UNOESTE contribuíram também com 0 evento, distribuindo mudas de árvores nativas da região a fim de incentivar o plantio de mudas no município de Presidente Pudente.

\section{Aplicação do questionário}

Com o intuito de avaliar o nível de conscientização da população em relação ao descarte dos resíduos eletroeletrônicos foi elaborado um questionário sem identificação pessoal, contendo onze questões, nove delas relativas ao descarte do lixo eletrônico. O questionário foi aplicado aleatoriamente às pessoas que participaram do mutirão.

Para avaliação do questionário foi utilizado o software Origin 6.0 onde se analisou através da estatística descritiva a frequência de cada questão respondida pelo entrevistado (BUSSAR, 2010).

\section{RESULTADOS E DISCUSSÃO}

Evento

Segundo a assessoria de imprensa da Universidade do Oeste Paulista, foram arrecadados cerca de 50 toneladas de resíduos eletroeletrônicos. Os equipamentos que se encontravam em bom estado para uso foram doados para o Fundo Social de Solidariedade de Presidente Prudente que encaminhará às famílias ou instituições conveniadas, e, os demais foram destinados a Associação de Recicladores de Lixos eletrônicos, ONG E-Lixo, de Londrina, Paraná, especializada na descaracterização e reciclagem destes tipos de resíduos.

\section{Questionário}

O questionário foi aplicado à 73 pessoas participantes do evento. Dos entrevistados, $73 \%$ são do sexo masculino. Em relação à faixa etária, a maioria dos entrevistados (40\%) possui idade entre 41 e 55 anos, como mostra a Figura 1.

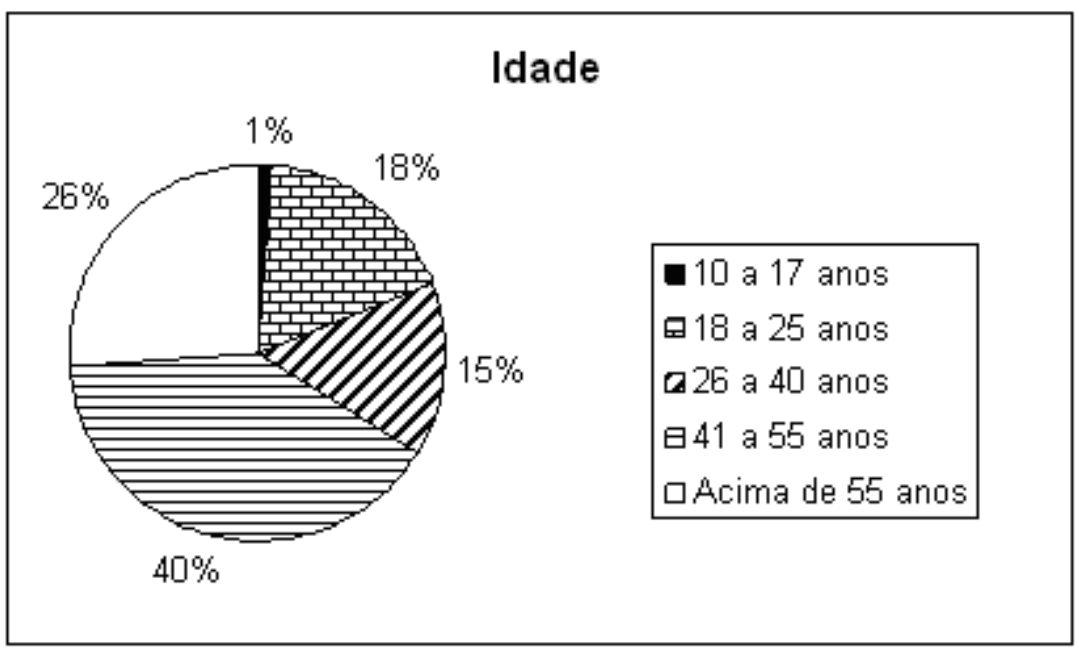

FIGURA 1 - Faixa etária dos entrevistados 
O evento foi divulgado de diversas formas, mas o veículo de comunicação que mais contribuiu com a divulgação do evento foi a televisão; isso justifica a presença de pessoas com idade entre 41 a 55 anos no mutirão, pois estas se interessam mais por programas de televisão de informações como, por exemplo, telejornais (FIGURA 2).

Os materiais levados pelos entrevistados no mutirão foram: monitores, teclados, impressoras, mouse, scaner, bateria de laptop, memórias, placa mãe, celulares, pilhas, MP3, rádio, aparelho de DVD, bateria de celular, carregador de celular, telefone, calculadora, controle remoto, cooler, disquet, CD, fax, vídeo cassete, ferro, fonte, lanterna, máquina fotográfica, no-break, pen drive, purificador de água, ventilador e vídeo game. Mas, a maioria dos contribuintes levou computadores completos, $17 \%$, e celulares, 17\% (FIGURA 3).

Quanto à origem do e-lixo doado pelos entrevistados $89 \%$ é de uso doméstico, enquanto os $11 \%$ restantes são oriundos do local de trabalho dos participantes.

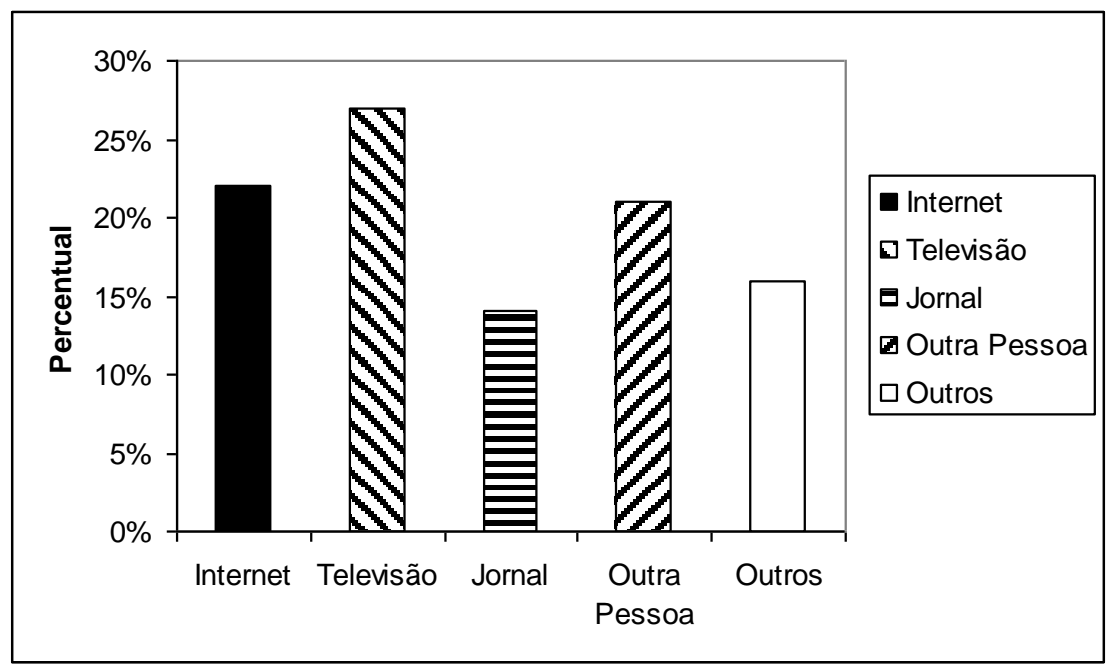

FIGURA 2 - Meio de comunicação pelo qual os entrevistados ficaram sabendo do evento

Em relação ao tempo em que os aparelhos estavam guardados, $43 \%$ dos entrevistados guardavam os resíduos eletroeletrônicos em um período compreendido entre 1 a 3 meses (FIGURA 4). 


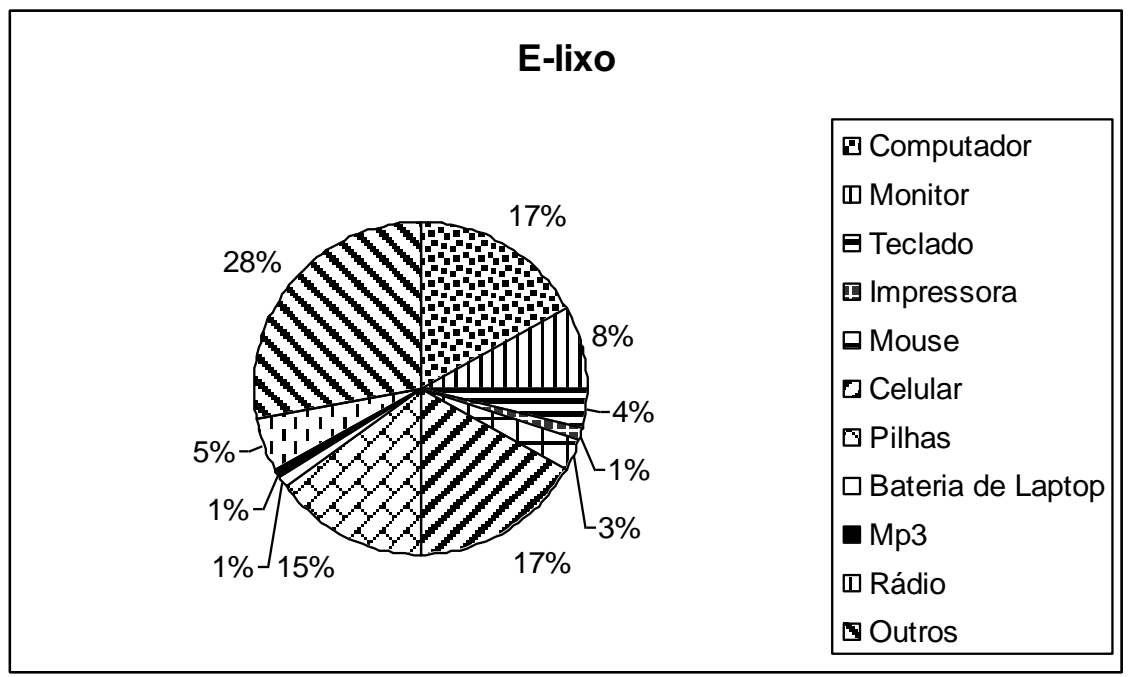

FIGURA 3 - Resíduos eletroeletrônicos doados pelos entrevistados

Observou-se que $63 \%$ dos entrevistados não sabiam que ao levarem seus resíduos ao mutirão receberiam em troca um cupom para concorrerem a diversos prêmios. Dentre os motivos apontados pelos entrevistados para o descarte dos resíduos eletroeletrônicos encontram-se: $58 \%$ tinham a finalidade de descarte, objetivando não guardar resíduos desnecessários em casa, $38 \%$ levaram seus resíduos para dá-los uma destinação correta e o restante, ou seja, $4 \%$ foram motivados pelo recebimento do cupom.

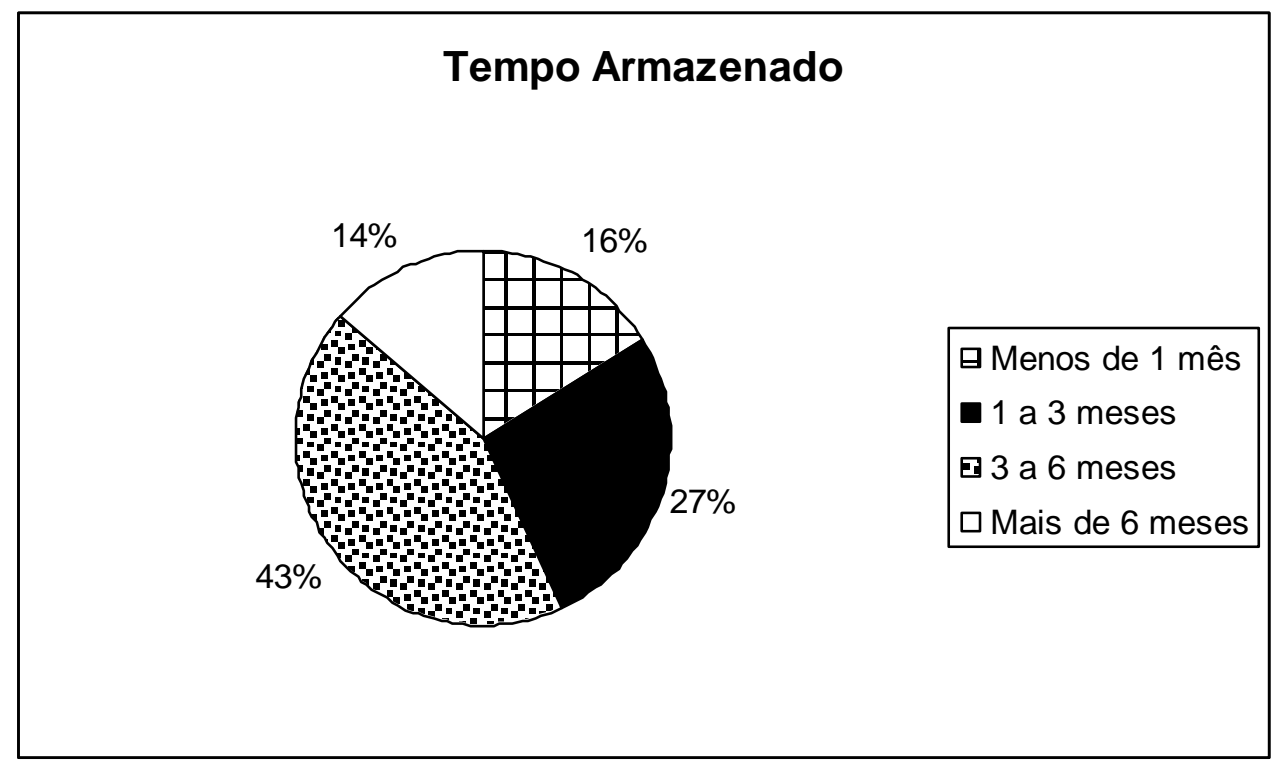

FIGURA 4 - Tempo em que o lixo eletrônico estava guardado

Dentre os 73 entrevistados, quatorze, $19 \%$, disseram descartar o lixo eletrônico no 
lixo de suas casas, dentre estas, 71\% alegaram descartar tais resíduos no lixo por não saberem o que fazer com os mesmos.

\section{CONCLUSÃO}

Foi possível observar, através da análise dos dados, que a grande maioria dos entrevistados (58\%) foi motivada, mais pelo desejo de se desfazer de materiais que consideravam desnecessários que pelo anseio em contribuir para com o meio ambiente. É válido ressaltar que mesmo aqueles que desejavam apenas se "livrar" dos resíduos eletroeletrônicos contribuíram, de maneira indireta, para com o meio, haja vista que $89 \%$ dos entrevistados afirmaram não descartar tais resíduos em lixos comuns, revelando assim, certo nível de consciência ambiental.

Outro fato que merece destaque é a falta de programas municipais, em especial no município avaliado, que contemplem ações de gerenciamento e até mesmo trabalhos de educação ambiental capazes de suportar a demanda populacional em relação ao descarte de tais resíduos, haja vista que alguns entrevistados alegaram não saber o que fazer com esse tipo de material.

\section{REFERÊNCIAS}

\section{FILHO, G. G. Meio Ambiente \&}

Consumismo. São Paulo: Editora Senac, 2008.

LIMA, L. M. Q. Lixo: Tratamento e Biorremediação. 3.ed. São Paulo: Hemus, 2004.

BRAGA, B. et al. Introdução à Engenharia Ambiental. São Paulo: Prentice Haal, 2002.
BiDONE, F. R. A; POVINELLI, J. Conceitos Básicos de Resíduos Sólidos. São Carlos: EESC/USP, 1999.

QUINTALHINA, L. A gestão sustentável do resíduo eletroeletrônico. Rev. Meio Ambiente Industrial,São Paulo: Tocalino LTDA, v. 14, n. 81, p. 24 - 39, Set/Out. 2009.

FERREIRA, J.; FERREIRA, A. A sociedade da informação e o desafio da sucata eletrônica. Rev. Ciências Exatas e Tecnologia,São Paulo: Anhanguera Educacional S.A., v. 3, n. 3, p. 157-170, Dez/2008. Disponível em:

$<$ http://sare.unianhanguera.edu.br/index.php/rc ext/article/viewPDFInterstitial/417/413>.

Acesso em: 05 ago/2010.

UNIVERSIDADE DO OESTE PAULISTA. Acessoria de Imprensa UNOESTE. 3ํMutirão do Lixo Eletrônico arrecada 50t de materiais. 28 de jun/2010. Disponível em: <http://www.unoeste.br/site/destaques/Noticias .aspx?id=4102>. Acesso em: 20 ago. 2010.

UNIVERSIDADE DO OESTE PAULISTA. Acessoria de Imprensa UNOESTE. 3ำ Mutirão do Lixo Eletrônico arrecada 50t de materiais. 18 de jun/2010. Disponível em: $<\mathrm{http}$ ://www.unoeste.br/site/destaques/Noticias .aspx ?id=4064>. Acesso em: 20 ago. 2010.

FEAM- Fundação Estadual do Meio Ambiente, 2009. Diagnostico da geração de Resíduos Eletroeletrônicos no Estado de Minas Gerais. Disponível em: $<$ http://www.feam.br/noticias/1/614-feamlanca-estudo-sobre-residuos-eletroeletronicos acesso em 02/09/2010 as 9h41>. Acesso em: 22 ago. 2010.

BRASIL. Lei no. 12.305, de 02 de agosto de 2010. Dispõe sobre a Política Nacional dos Resíduos Sólidos. Disponível em: <http://www.planalto.gov.br/ccivil_03/_Ato2007 -2010/2010/Lei/L12305.htm>. Acesso em: 06 de Set/2010.

MOTA, S. Introdução à Engenharia

Ambiental. São Paulo: ABES, 1997. 